\title{
El grupo Paralelo, una instancia mediadora en la cultura de Aguascalientes
}

ALICIA DE JESÚS GIACINTI COMTE*

Departamento de Letras/UAA

\section{RESUMEN}

A fines de los años cincuenta, al tiempo que en la ciudad de México empiezan a cambiar los horizontes culturales, aparece en Aguascalientes la revista Paralelo. Los editores y colaboradores de esta revista rechazan beligerantemente el centralismo cultural ejercido desde la ciudad de México y pugnan por la modernización cultural de Aguascalientes. Este artículo ofrece una revisión crítica de la trayectoria seguida por esa revista y el grupo que la publicó entre 1957 y 1962.

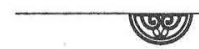

ABSTRACT

The Paralelo GRoup, a mediator instance in the Culture of AGUascalientes

\begin{abstract}
A the end of the 1950s, while the cultural horizons in Mexico City begin to change, the magazine Paralelo appears in Aguascalientes. The publishers and writers of this magazine reject the cultural centralism and fight in behalf of cultural modernization in Aguascalientes. This article offers a critic view of the trajectory of this magazine and the group that published it between 1957 and 1962.
\end{abstract}




\section{INTRODUCCIÓN}

En los años cincuenta, Aguascalientes tenía un campo cultural que a los ojos de algunos intelectuales hidrocálidos de avanzada, era anacrónico en comparación con el de la capital del país, aunque no lo era respecto a otras poblaciones con características semejantes. En ese momento es cuando irrumpe en la cultura local un grupo que inicialmente se denominó Asociación Cultural de Aguascalientes (ACA) y posteriormente se transformó en el grupo Paralelo. Como tal, su labor mediadora abarca el periodo de 1957 a 1963 y quizá un poco más allá.

El grupo Paralelo estuvo conformado por jóvenes escritores que marcaron un momento muy importante en la cultura de Aguascalientes. En su proyecto estaban implicadas tanto la lucha contra el centralismo cultural como la modernización del campo literario de la entidad. Para la realización de sus ideales no dudaron en enfrentarse con publicaciones ampliamente reconocidas, incluso criticaron fuertemente a figuras ya canonizadas.

Para entender su postura, es importante describir el campo cultural nacional (¿o de la Ciudad de México?) que prevalecía en los momentos previos a la aparición del grupo y

- Considero importante destacar el apoyo del Lic. Salvador Gallardo Topete, integrante del grupo Paralelo, para la realización de este trabajo. El Lic. Gallardo me facilitó los ejemplares de la revista y algunas publicaciones de la editorial y aceptó aclarar toda clase de dudas y responder a determinados cuestionamientos. En una de esas entrevistas me enteré que Ricardo Ortiz Tamayo, cuya firma aparece en algunos artículos, fue un seudónimo creado colectivamente entre varios de los integrantes del grupo, en especial de Víctor Sandoval y del entrevistado. Ya casi para terminar el escrito le pregunté si seguían, actualmente, sosteniendo la crítica adversa que hacen en la revistan acerca de algunas figuras consagradas de la literatura nacional. Su respuesta fue que, al menos, él sí seguía pensando igual. 
así, darnos cuenta de los motivos de su existencia. Más adelante analizaré sus ideas y, posteriormente, las polémicas en las que se enfrascaron o pretendieron enfrascarse. Digo pretendieron, pues no tengo evidencia de que hayan obtenido respuesta a sus inconformidades, tal vez debido al mismo centralismo que ellos condenaron.

A mediados del siglo XX, Aguascalientes era una pequeña ciudad con toda la quietud y la tranquilidad que reinaban por ese entonces en las ciudades que, aunque capitales de estado, no habían entrado aún en el vertiginoso ritmo de vida de los grandes centros de población nacionales, menos aún en el de la ciudad de México. Había una tradición cultural desde el siglo XIX. Sin embargo, los artistas e intelectuales más notables, en su momento, decidían emigrar a la capital para encontrar situaciones más propicias de desarrollo intelectual y, sobre todo, con el objeto de obtener un reconocimiento a su obra.

Quienes decidían permanecer en su solar nativo, nunca eran considerados dentro del campo cultural nacional, ya que las comunicaciones eran difíciles. En la ciudad capital, los círculos intelectuales desconocían a quienes desarrollaban su labor artística a cientos de kilómetros de ellos y, si acaso sabían de ellos, los menospreciaban porque el arte en la provincia conservaba una tradición que a los ojos de los capitalinos, se había quedado muy atrás de las innovaciones que ellos estaban ya manejando.

EL CONTEXTO NACIONAL

En la ciudad de México, uno de los rasgos compartidos entre los escritores de la generación de los cincuenta era el anhelo de desprenderse del nacionalismo cultural que ya no significaba un método de cohesión y estímulo para la cultura, si- 
no más bien una "cansada fórmula de promoción oficialista" y "su manipulación política corría a cargo del partido del poder". ${ }^{2}$ Sin embargo, los intelectuales no comprometidos con los partidos de izquierda se alejaban y se acercaban alternativamente al mundo oficial, ya fuera aceptando puestos en el gobierno, en el servicio exterior, o bien obteniendo los premios que el mismo gobierno otorgaba.

Tanto Carlos Monsiváis como Abelardo Villegas destacan la importancia que tuvieron, para ese momento histórico y cultural, los ensayos de Daniel Cosío Villegas y Jesús Silva Herzog acerca de la agonía de la Revolución Mexicana. El primero propone como causa del fin de la revolución la corrupción político-administrativa y el segundo señala su aburguesamiento. Vicente Lombardo Toledano, a la cabeza de la izquierda mexicana, hacía aparecer al marxismo como un método que confirmaba la operatividad y la legitimidad de un estado fuerte; funda el Partido Popular que era y no era marxista ya que había asumido la doctrina prista, pero al mismo tiempo propugnaba por el socialismo. El Partido Comunista, muy mermado.ya, buscaba la ortodoxia en el campo intelectual; en el arte y en literatura se manifestaba por el "realismo socialista" originando fuertes polémicas entre sus mismos seguidores.

En el campo literario Juan Rulfo y Juan José Arreola son los modelos a seguir. El primero, autor de El llano en llamas y Pedro Páramo, renueva el proceso narrativo; el segundo, con su obra Varia invención postula la voluntad de la forma

${ }^{1}$ Carlos Monsiváis. Notas sobre la cultura mexicana en el siglo XX en Historia general de México. Tomo II, tercera edición, México, El Colegio de México, 1981, p. 1479.

${ }^{2}$ Abelardo Villegas. El pensamiento mexicano en el siglo XX. México, FCE, 1993, p. 185. 
y la perfección de la página. Nacionalistas y universalistas aplauden a Rulfo. Los primeros por la elección de sus temas, los segundos por la novedad y el rigor de su estilo.

Alberto Vital sostiene que hubo en ese momento un cambio de horizonte que condujo a la creación de un nuevo código, que era la síntesis de los rasgos fundamentales de los dos anteriores: el tratamiento de temas mexicanos por medio de técnicas modernas, que ya tenía un antecedente en Al filo del agua de Agustín Yáñez. Entre los poetas más importantes figuraban Rosario Castellanos, Rubén Bonifaz Nuño y los Jaimes, Sabines y García Terrés. La entonces novedosa televisión deja sentir su influencia. Monsiváis anota también, que aparece la que él llama "subliteratura de éxito", cuyos máximos exponentes son Luis Spota y Roberto Blanco Moheno, quienes se apoyan en técnicas de publicidad modernas. En 1958, Carlos Fuentes publica La región más transparente, y el mundo intelectual opina que se ha entrado a la modernidad literaria, lo que fue uno de los indicios del cambio de horizonte. "La novela ha abandonado los temas locales, pasó a primer plano la ciudad y con ella los problemas del hombre semejantes en toda sociedad urbana". ${ }^{3}$ Los intelectuales aspiran al reconocimiento internacional de su obra. En los años sesenta

...un grupo de jovenes literatos que apoyaba las nociones culturales y estéticas en las opiniones de Octavio Paz y de Rufino Tamayo pidieron, no sólo para la filosofía sino para la cultura mexicana, una superación del nacionalismo y una búsqueda de la universalidad. A este grupo se le apodó "La Mafia", porque monopolizaban las páginas de los suplementos culturales y especialmente de los que sucesivamente fundó Fernando Benítez, que resultaban los de más prestigio. ${ }^{4}$

${ }^{3}$ Luis Villoro. "La cultura mexicana de 1910 a 1960", en México entre los libros (Pensadores del siglo XX). México, FCE-El Colegio Nacional, p. 38.

${ }^{4}$ Abelardo Villegas, Op. cit., p. 203. 
Benítez se va convirtiendo poco a poco en el representante del poder ${ }^{5}$ en el campo literario, primero a través de México en la Cultura y después en La Cultura en México, en su grupo estaban Carlos Monsiváis, Juan García Ponce, José Emilio Pacheco, Luis Guillermo Piazza y el pintor José Luis Cuevas. ${ }^{6}$ De 1955 a 1965 se publica la Revista Mexicana de Literatura dirigida en principio por Carlos Fuentes y Emmanuel Carballo y más adelante por Tomás Segovia y Juan García Ponce. Elías Nandino edita Estaciones y varias universidades, además de la UNAM, tienen sus propias revistas literarias.

Grandes editoriales se ocupan de consagrar a los escritores, por ejemplo la tradicional Porrúa, Botas, Era y Joaquín Mortiz. Está también el Fondo de Cultura Económica que inicia su serie Letras Mexicanas, además hay otras más pequeñas como Gernika, FEM, V Siglos y Diógenes.

Se suceden acontecimientos impactantes en el ámbito nacional: el movimiento ferrocarrilero de Vallejo, la huelga de los médicos del Seguro Social, el asesinato del líder campesino Rubén Jaramillo; hechos a los que pocos les dan la importancia que merecen.

Los sectores ilustrados esquivan cualquier uso de la tradición y creen en la ruptura a la que entienden como su incorporación a lo más audaz del siglo. Su meta es la modernidad, su tono es el afán de brillantez, es la eclosión de suplementos. y revistas, conferencias, entrevistas a intelectuales en tele-

\footnotetext{
${ }^{5}$ Algunos intelectuales decían que el verdadero poder tras el trono era Octavio Paz, quizá por la fuerte influencia que comenzaba a tener en el campo cultural mexicano y que conservó hasta su muerte.

${ }^{6}$ Respecto a Cuevas, la revista Paralelo dice que es "un jovencito que pinta y escribe en dólares" que "tiene la audacia de invocar los nombres altísimos de Posada y Orozco para justificar su grotesca postura artística" (Paralelo, Núm. 5, p. 2) Con el tiempo este "jovencito" se ha convertido en uno de los máximo exponentes de la pintura mexicana.
} 
visión. Muchos son apasionadamente colonialistas porque no piensan en el colonialismo como una derrota sino como un avance. Se habla del "provincianismo" con desprecio. La cultura es propiedad exclusiva de la capital, abundan los reconocimientos, hay "el afán de disponer no de una tradición sino de antecedentes prestigiosos. Se nulifican las categorías sentimentales de provincia y hogar". "También se pone de moda el mundo prehispánico y la generación de Los Contemporáneos es objeto de múltiples reconocimientos y homenajes mientras sus obras se editan lujosamente.

El acontecimiento internacional que marca esta época es la Revolución Cubana y, desde La Habana, la recién fundada Casa de las Américas propone formas específicas de política cultural que muchos intentan seguir.

\section{GÉNESIS DEL GRUPO PARALELO}

Durante estos años, en Aguascalientes surge también una gran inquietud por integrarse a la vida cultural de la nación. El ambiente intelectual de la ciudad ha estado sumido en una dulce quietud. Sólo en el paréntesis que significaba la Feria de San Marcos con sus Juegos Florales, los poetas procuraban sacar lo mejor de su producción, con la esperanza de obtener el galardón y también, hay que decirlo, el premio en efectivo. ${ }^{8}$ El triunfo de ese certamen se otorgaba a un solo poema que el Jurado, formado en ocasiones por figuras representativas de la cultura nacional, consideraba el mejor. Los poetas hidrocálidos incursionaban también en otros

Monsiváis. Op. cit. p. 1492.

${ }^{8}$ Salvador Gallardo Topete comenta que con los premios obtenidos en los Juegos Florales de varias ciudades del país. solventaban los gastos de impresión y distribución de su revista. 
concursos de diversos lugares de la República y triunfaban frecuentemente. ${ }^{9}$ Las veladas en las que se entregaba el premio contaban con la presencia de connotados intelectuales que fungían como mantenedores. ${ }^{10}$

Hacia principios de los cincuenta se comienza a ver una actitud de cambio en el que tendrá mucho que ver Salvador Gallardo Dávalos, ${ }^{11}$ quien formó parte del grupo Estridentista. ${ }^{12}$ Gallardo Dávalos se había avecindado en la ciudad de

9 Se decía, por aquellos años, que el poeta Jesús Reyes Ruiz tuvo como meta conseguir quince flores naturales para regalarlas a su hija Concepción Angélica, el día que cumpliera quince años.

${ }^{10}$ Los mantenedores eran quienes tenían a su cargo el discurso oficial de la ceremonia de premiación. Entre los años 1956 y 1963, que son los que abarca este ensayo, fungieron como tales Jesús Reyes Ruiz y los también poetas Elías Nandino, Roberto Cabral del Hoyo y Celestino Gorostiza. Uno de los galardonados fue el poeta Víctor Sandoval, del grupo Paralelo. Antes y después de esas fechas, fue triunfador en varias ocasiones Rubén Bonifaz Nuño.

11 Salvador Gallardo Dávalos, médico de profesión, nació en Río Verde SLP. Sus primeras obras fueron publicadas por Germán Liszt en Puebla. Ricardo Esquer, en Aguascalientes, estancias y senderos. Poesía, novela, ensayo y teatro, 1993, escribe :"En principio se le podría ubicar en la generación de López Velarde por el modo de percibir el clima humano de la provincia, aunque después sus ensayos, sus artículos y dramas adoptan el punto de vista del materialismo histórico, lo que no dejó de dar a sus escritos un perfil doctrinario y en ocasiones panfletario".

${ }_{12}$ El Estridentismo fue un movimiento artístico mexicano, derivado de los movimientos de vanguardia europeos nacidos a partir de 1909 con el $F u$ turismo. "El Estridentismo nace e irrumpe en los últimos días del mes de diciembre de 1921, con la aparición de la hoja volante Actual No. 1, redactada y firmada por Manuel Maples Arce y apoyada por un Directorio de Vanguardia, posiblemente extraído de algunas revistas de la vanguardia internacional" escribe Luis Mario Schneider en El Estridentismo o Una literatura de la estrategia. INBA, 1970, p. 35. Como todos los escritores de vanguardia, los estridentistas pretendían hacer algo totalmente original y novedoso, se caracterizaban también por sus actitudes iconoclastas y agresivas contra lo establecido. Schneider también anota :"Eran esencialmente renovadores y por eso atacaban y zaherían a los escritores tradicionalistas o conservadores, y odiaban a quienes concebían cualquier estética". Ibid. p. 208. Para 1926, el 
Aguascalientes desde el año 1927, y aunque "llegó produciendo poemas de tintes universales, logra introducirse al cerrado ambiente de provincia escribiendo según los requerimientos del lugar"13 para, llegado el momento, provocar la transformación y el cambio cultural.

Gallardo Dávalos reunió a su alrededor a un grupo de jóvenes, entre los que se contó su hijo mayor, en quienes despertó la inquietud por la literatura y con los que, inicialmente, formó la Asociación Cultural de Aguascalientes (ACA), y después el grupo al que denominaremos Paralelo, tanto por el nombre de la revista que durante seis años publicaron, como por el de la editorial que fundaron. La revista y la editorial fueron los medios en los que dieron a conocer su producción literaria ${ }^{14}$ y las ideas que sustentaban. Formando parte de aquel grupo de jóvenes escritores estaban Víctor Sandoval, Desiderio Macías Silva, Salvador Gallardo Topete, Rolando Mora Ruiz y Guillermo García Varela, entre otros, "escritores que demandan un lugar en el contexto de la cultura nacional", hombres que "se sitúan ante la realidad y ante el lenguaje con la actitud del mejor de los poetas". ${ }^{15}$ Una de las obsesiones del arte en Aguascalientes por esos

movimiento Estridentista estaba prácticamente en extinción. Además de Maples Arce y Gallardo Dávalos fueron miembros importantes del movimiento Arqueles Vela, Germán List Arzubide, y Luis Quintanilla.

${ }^{13}$ Alejandro Sandoval. Poesía en Aguascalientes. Antología de poetas (siglos XIX y XX), México, Editorial Oasis, 1984, pp. 8-34.

${ }_{14}$ Entre las obras de Editorial Paralelo que he tenido en mis manos están los poemarios: Veredictos de Polvo de Desiderio Macías Silva, 1959, Caín y Abel, 1960 y Raíces 1963, así como una hermosa presentación individual de un poema con imágenes desgarradoras titulado "Desanclaje", los tres últimos de Salvador Gallardo, el Hijo. Se hicieron plaquetas de otros poetas pero eran ediciones muy limitadas, por lo que se deberán rastrear con más tiempo. La editorial sobrevivió a la revista.

is Alejandro Sandoval, Op. cit. 
años es el amor por lo regional y por las experiencias de la vida local, quizá por temor a los cambios, cambios que se van a dar, pese a todo, un poco por la labor del grupo de seguidores de Gallardo Dávalos.

\section{El Proyecto de Paralelo y SUS IDEAS}

La revista Paralelo ve la luz en junio de 1957. En la primera página del primer número, destaca el manifiesto del grupo aunado a su programa. El tono de este texto es, anacrónicamente, estridentista y, obviamente, está firmado por Gallardo Dávalos, la colaboración se titula "Aquí, Paralelo 21"16 y se inicia con las siguientes líneas:

\section{¡SE ESTÁ INCENDIANDO EL PICACHO ! ¡El Cerro}

del Muerto se levanta de su sueño milenario con un estandarte en llamas! Con él proclama

la independencia cultural del altiplanoji ${ }^{17}$

Gallardo Dávalos compara a los centros de poder cultural con los meridianos que exigen sumisión, rechaza a los "meridianos imperialistas" y a los "meridianos modistos", ${ }^{18} \mathrm{y}$

${ }^{16} \mathrm{El}$ paralelo 21 es el que pasa precisamente por Aguascalientes.

"El Cerro del Picacho forma parte del llamado Cerro del Muerto que está situado al occidente de Aguascalientes y es considerado uno de los símbolos de la ciudad. En esta cita, y en todas las que tome de Paralelo, respeto la ortografía y la sintaxis originales.

${ }^{18}$ ¿Será todavía una referencia al grupo de Los Contemporáneos? ¿Un resto de la llamada "polémica de la literatura viril"? El grupo de Los Contemporáneos, del que formaron parte Salvador Novo, Carlos Pellicer, Xavier Villaurrutia, Jorge Cuesta, Gilberto Owen y Jaime Torres Bodet, y el de Los estridentistas se enfrascaron en una polémica acerca de cómo debería de ser la literatura. Los segundos aseguraban que lo que escribían Los Contemporáneos era afeminado. 
propone "garrote" para los "académicos-realistas". Destaca que "los paralelos [ellos, la Provincia] $]^{19}$ son autónomos e independientes", exige "estorbar la irrupción hacia él [el "meridiano del Anáhuac", como llama en este manifiesto a la Ciudad de México] de todo lo mejor de la Provincia" e impedir que "cerebros tránsfugas vayan a ser exprimidos en las metrópolis absorbentes". En este manifiesto encontramos la síntesis de todas las ideas que van a ser desarrolladas en los veinte números publicados a lo largo de seis años: están contra el centralismo cultural y sus grupos de poder, contra la emigración de intelectuales a la capital, contra muchos escritores canonizados, en fin, están contra todo lo que implique sumisión, llámese Academia, Iglesia o Norteamérica, no necesariamente en ese orden. Termina con una frase contundente que van intentar hacer posible relacionándose con otros grupos semejantes:

\section{¡PROVINCIANOS DE LA REPÚBLICA, UNÍOS!}

En el número 10, página 5, Gallardo Dávalos "echando una mirada retrospectiva" a lo que ha sido la revista, refrenda su posición contra el centralismo, y asegura "nuestras columnas estarán abiertas para todos y para todas las buenas causas [...] las del pueblo", reitera: "La orientación que hemos dado a nuestra publicación [...] es en defensa, prosperidad y cultura del pueblo y en defensa también de la provincia contra la voracidad absorbente de la metrópoli". El autor expresa con sinceridad: "nuestras fuerzas son pocas y muchos los obstáculos con que venimos tropezando y escasos los elementos que nos brinda nuestro medio", añade "el

${ }^{19}$ Todo lo que aparece entre corchetes es mío. 
esfuerzo conjunto y metódico [...] acabarán [con la] soberbia, [la] mezquindad y el obscurantismo".

Las raíces estridentistas de Gallardo Dávalos se perciben en éste y en otros textos de Paralelo. Son absolutamente claras en una "entrevista" que aparece en el número 8 de $P a$ ralelo firmada por Rolando Mora Ruiz. En ella, el "entrevistado", Ricardo Ortiz Tamayo, ${ }^{20}$ responde a la pregunta acerca de como encuentra la situación cultural en la provincia:

Sería bueno hacer una quema $a^{2 l}$ de todos los intelectuales de provincia que padecemos; acabar con los profesionistas improvisados como profesores de literatura, junto con sus textos [...].Arrasar esos famosos Ateneos, sociedades culturales, Certámenes de Poesía, Juegos Florales y demás manifestaciones culturales de esa indole. ${ }^{22}$

En una de las secciones fijas de la revista llamada "Paralelogramos", se refieren a una reunión de los antiguos estridentistas "ya corregidos y sin violines estrangulados ni andamios ni aleros" para despedir a Manuel Maples Arce que partió rumbo a Europa. ${ }^{23}$

En el artículo titulado "El estridentismo y la piratería de agua dulce" el propio Gallardo Dávalos reafirma la convicción revolucionaria de sus antiguos compañeros y destaca las aportaciones que hicieron a la poesía. Reconoce que el Estridentismo ya pasó, pero asegura que su fin no fue por una cobarde huida, sino que "comprendimos que el pueblo no se

\footnotetext{
${ }^{20}$ Este colaborador ficticio era, según sus creadores, un profesor rural que había estado en Europa becado por una institución nacional. Estuvo, supuestamente, en París cuando era embajador Torres Bodet a quien acusa de discriminar a sus compatriotas.

${ }^{21}$ Las cursivas son mías. La sintaxis se respeta.

${ }^{22}$ Paralelo, núm. 8, p. 3.

${ }^{23}$ Paralelo, núm. 13-14, p. 2.
} 
beneficia con versos que no comprende [...] creemos que primero hay que enseñar a leer [...] darles una cultura media a los más...". ${ }^{24}$

Las referencias anteriores, aunadas a la rebeldía contra lo establecido y el lenguaje, áspero en ocasiones, son lo que queda del estridentismo en Gallardo Dávalos, aunque no es difícil encontrar huellas del movimiento en algunas imágenes poéticas y en las actitudes de sus jóvenes discípulos y colaboradores en Paralelo. ${ }^{25} \mathrm{Y}$ es que ellos lo consideraban "un guía y un maestro". ${ }^{26}$

La orientación principal de Paralelo, es la oposición al centralismo en la cultura y está expresada de diferentes maneras en sus artículos editoriales y en los ensayos. Desde el número 1 de la revista, en la página 2, manifiestan que aceptan al Distrito Federal como el "centro vital de la República", pero no le reconocen el derecho de "querer abarcar [...] todos los aspectos de la vida cultural, política y económica de México". En el número 5, página 3, escriben: "reconociendo a la ciudad de México como cerebro y corazón de la República, seguiremos luchando por una comprensión mejor para la provincia". Según ellos, la provincia "muere ahogada por la mediocridad y la falta de recursos económicos destinados a mejorar las instituciones culturales y educativas".

\footnotetext{
${ }^{24}$ Paralelo, núm. 16-17, 1960, p.3.

${ }^{25}$ Algunos ejemplos de estas huellas del estridentismo en los jóvenes poetas de la revista son :"Las palabras errantes y amarillas/ que se desprenderán/ con el asesinato de las esquinas/ de los faroles mercuriales", en el poema titulado Las palabras de Víctor M. Sandoval, Paralelo, núm. 1. "...cada casa tenía/ una noria de tedio/ para el suicidio de la tarde/ y un limonero enjuto/ para adelgazar la sangre", poema titulado Raiz de Hastío de Salvador Gallardo, el Hijo, en Raíces, Editorial Paralelo, Aguascalientes, México, 1963.

${ }^{26}$ Paralelo, núm. 13-14, p. 3.
} 
Sin embargo, están conscientes de que falta mucho camino por andar. Víctor Sandoval, uno de los pilares de la revista, aseguró que Aguascalientes estaba cincuenta años atrás en materia cultural. Los editores sostienen que eso era cierto y que se había quedado corto, porque "vivimos todavía en la baja Edad Media". ${ }^{27}$ Más adelante, en la ya mencionada entrevista ficticia con el colaborador de Paralelo, Ortiz Tamayo, se escribe : "en la provincia no existe nada. Si acaso alguna señal aislada que prematuramente se marchita y se pierde por falta de la debida orientación". Sandoval en una carta a José G. Zuno, (respuesta a otra que el jaliciense envió a la revista), justifica la emigración de los artistas porque "nosotros no supimos darles lo que ellos necesitaban para su obra creadora", y ahora ellos "se han olvidado de la Provincia y únicamente se acuerdan de ella cuando ésta les llama para ofrecerles ridículos homenajes o cuando el nombre del solar nativo es vinculado a algún acontecimiento nacional. ${ }^{.28}$

Uno de los artículos más fuertes en contra del centralismo cultural es el editorial del número 11 firmado por José Antonio Montero quien se manifiesta indignado por algunos comentarios hechos en México en la Cultura (número 508) acerca de la "penuria cultural de la provincia". ${ }^{29}$ Montero sostiene que a las publicaciones literarias les gusta enmascarar la verdad y que "las controla una pandilla", "el PRI literario", que es "quien señala colaboradores y fija el material literario para utilizarse en las diversas revistas". Se pregunta

${ }^{27}$ Paralelo, núm. 2, p. 2.

${ }^{28}$ Paralelo, núm. 9, p. 2.

${ }^{29}$ Gloria Patricia Cabrera en su tesis doctoral de la UNAM, 1997, inédita, La sombra de José Revueltas, escribe que Benítez, director de La Cultura en México, explicaba su proyecto cultural a partir de la antinomia universalismo contra nacionalismo-provincianismo y su grupo trabajaba para quitarle a la cultura el "nacionalismo ridículo".

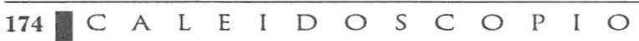


luego, con un dejo de ironía, si la pobreza cultural de que acusan a la provincia no la sufre también la capital, ya que en algunas de las publicaciones del interior escriben los mismos que suelen escribir para las de la capital. ${ }^{30}$ Lamenta "la soberbia de los capitalinos acaparadores de la cultura". Menciona como contraparte a muchas revistas independientes de San Luis Potosí, Jalapa, Nuevo León, Jalisco y Michoacán con sus nombres, y en general, otras de "Puebla, Chiapas, Aguascalientes, Querétaro y otros lugares del país [...] que salen a la búsqueda del público con material digno de figurar en las capitalinas y en otras revistas de más prestigio y libertad". Más adelante reafirma que hay "un asfixiante monopolio del arte que impide la aparición de nuevos brotes, nuevas luces, nuevos y más amplios horizontes" y concluye contundente que la verdadera penuria cultural no es la de la provincia sino "la que prohijan quienes se creen depositarios a perpetuidad de la cultura nacional". ${ }^{31}$

Por otro lado, Paralelo ataca constantemente al malinchismo de la provincia en la que "hay un clima hostil para toda manifestación cultural principalmente si es de carácter local o mexicano", un "volverle la espalda a lo nacional y a lo poco que en materia artística se produce en los Estados". Esto, como ya se mencionó, es una característica de la cultura de la época y no es privativa de las ciudades pequeñas y en lo personal no creo que, a casi cuarenta años de distancia, haya desaparecido del todo.

${ }^{30}$ El editorialista se refiere a las revistas de las universidades de Nuevo León y de Veracruz en las que colaboraban Pascual Buxó, Emilio Carballido, Raúl Leyva, Sergio Galindo, Antonio Castro Leal y otros que también escribían en la de la UNAM y en los suplementos culturales de los periódicos capitalinos.

${ }^{31}$ Paralelo, núm. 11, pp. 1 y 2. 
A pesar de ser ellos mismos concursantes asiduos de Juegos Florales, consideran estos certámenes como una causa del atraso cultural de Aguascalientes. En el número 2 escriben :"la fauna de poetisos multifloreados crece cada día [...] cada uno[...] se cree genio." Se consuelan, en el número ocho, porque "no hay poeta de Juegos Florales que dure cien años ni cristiano que lo aguante". En el número 12 hay un editorial titulado "Juegos Florales, sociedad irresponsable", firmado por Ortiz Tamayo. Arremeten duramente contra estos certámenes literarios, aunque recuerdan que José Luis Martínez, en Problemas literarios, señala, con gran acierto, que casi todos los poetas que se inician caen en esa tentación. ${ }^{32}$ Sin embargo, ellos no se limitan a atacar este tipo de concursos; a cambio, aportan una idea que va a cristalizar en 1968 con la creación del Premio Nacional de Poesía. Proponen que se realice un certamen en el cual se premie no a un solo poema, sino a una obra completa.

Paralelo tiene una orientación hacia la izquierda, de acuerdo a la ideología de su guía. Se preocupa por los obreros y su cultura porque tal parece que "la única cultura que los obreros tienen derecho a poseer es aquella que escasamente toca los linderos del conocimiento". Encontramos también una referencia a la formación de una Unión de Trabajadores Intelectuales de Aguascalientes, perteneciente a la Confederación Nacional de Organizaciones Populares del PRI. ${ }^{33} \mathrm{Y}$ aquí es importante señalar que en varios números se

${ }^{32}$ Y los iniciados también. En el lapso que nos ocupa fueron triunfadores en los Juegos Florales de Aguascalientes Gloria Riestra, Víctor Sandoval, José Rosas Cansino en 1959, Agustín Ayala y Abigael Bohórquez. Desiderio Macías Silva también se hizo acreedor a la Flor Natural en años posteriores. Triunfador en varias ocasiones fue Rubén Bonifaz Nuño.

${ }_{33}$ ¿Sería algo así como la Liga de escritores y artistas revolucionarios, LEAR, pero gobiernista? 
apoya la política de ese partido. ${ }^{34}$ Por ejemplo, la campaña de Adolfo López Mateos fue dirigida por Alfredo de Lara Isaacs, luego senador por Aguascalientes. De Lara era miembro del grupo desde los tiempos de la ACA y fue también colaborador de Paralelo, en donde destacó como cuentista.

La sociedad de Aguascalientes era, en los años cincuenta y sesenta, tradicional y profundamente religiosa por lo que, según dicen en Paralelo, algunos de sus artículos produjeron escozor en algunos grupos, y así fue en realidad. Se habla en ocasiones contra la Iglesia Católica, aunque sin nombrarla abiertamente, como promotora de campañas contra el libro de texto gratuito: "las alimañas que produce la educación primaria en México, llámense maristas, verbos encarnados, gachupines y libreros monopolistas han intensificado a últimas fechas su antipatriótica campaña en contra del Libro de Texto Gratuito." ${ }^{35}$ Se insiste mucho en el cumplimiento del artículo 3o. constitucional aduciendo que en los colegios particulares la educación no es laica ${ }^{36}$ y que luchan por derogar ese precepto constitucional. Estas preocupaciones están muy alejadas de la literatura, pero nos ayudan a entender la ideología del grupo que convive, en mayor o menor proporción, con su ideología estética. ${ }^{37}$

${ }^{34}$ Gallardo Dávalos fue dirigente del PNR en Aguascalientes. Más adelante, cuando el partido ya se llamaba PRI, el poeta fue senador.

${ }^{35}$ Paralelo, núm. 16-17, p. 6.

${ }^{36}$ Como sabemos, el artículo tercero de la Constitución Mexicana señala que la educación debe ser laica, mandato que no se cumplía en algunas de las escuelas privadas. Sin embargo, nadie ignora que los mismos funcionarios de gobierno inscribían a sus hijos en colegio particulares.

${ }^{37}$ Ideología en el sentido de elaboración conceptual sistemática de una serie de experiencias, necesidades y aspiraciones relativas a una esfera de la cultura, conforme a un deber ser ideal que se va construyendo como un discurso. La formación ideológica estética según François Peruse es un conjunto de posiciones, definiciones, conceptualizaciones del arte, literatura 


\section{RELACIÓN DE PARALELO CON OTROS GRUPOS DE POETAS}

Paralelo fue el fruto del esfuerzo de un grupo de jóvenes escritores que con todo el entusiasmo de sus pocos años y bajo la tutela de Salvador Gallardo Dávalos irrumpen en el ambiente de Aguascalientes con sus ideas y su producción literaria. Sin patrocinio alguno, salvo por un pequeño anuncio que aparece a partir del número 5 (el inicial como reseña de un evento), sostienen la revista con aportaciones de algunos de sus amigos y de ellos mismos. Con estos precarios medios van a hacer la revista que distribuirán localmente y enviarán a círculos intelectuales del país y del extranjero, en especial a quienes tenían publicaciones semejantes, los que, a su vez, les harán llegar sus propias revistas y, en ocasiones, también sus colaboraciones.

El contacto en la ciudad de México va a ser más frecuente con los jóvenes de la revista Metáfor ${ }^{38}$, que no eran muy bien vistos en el campo literario "oficial". Quizá de esa revista y de otras de esa época tomaron la idea de publicar las pequeñas notas sarcásticas, irónicas o humorísticas que estaban de moda en las revistas literarias ${ }^{39}$ y que en Paralelo se llamaron "Paralelogramos".

etc. que están coexistiendo, unas más fuertes que otras. Sus límites no son tan claros como en la política.

${ }^{38}$ Entre escritores de Metáfora estaban Antonio Silva Villalobos y Jesús Arellano, de quien Huberto Batis aprendió todo lo que debía saber para editar, según su propia confesión en Lo que cuadernos del viento nos dejó, México, Conaculta, 1994, p. 20. Ambos, Silva y Arellano tuvieron amistad con los de Paralelo y colaboraron en varios números.

${ }^{39}$ Batis. Op. cit., p. 69, escribe acerca de los "Palos de Ciego" de Metáfora: "Eran chismes inocentes, frecuentemente infantiloides y babosos, que servían para informar, subrayar, hacer puntadas, protestar y hasta algunas vez denunciar. Los agrios colofones de Jesús Arellano en Me(n)táfora eran emulados, pues con inocentadas, sin la malicia que tenían en la Revista Mexicana de Literatura las 'Actitudes' y acaso sin lo pesadito de 'La feria de los días', la sección sin firma de Jaime García Terrés en la Revista de la UNAM". 
Paralelo publica, además de las creaciones literarias del grupo, las obras de otros poetas reconocidos en el campo nacional como Rubén Bonifaz Nuño, Jesús Arellano y Antonio Villalobos. Hay también obra de extranjeros como Alfredo Cardoña Peña y la cubana Dulcila [Dulce] Cañizares. En uno de los números aparece un "Homenaje a la Poesía Chilena", que consiste en una selección de poemas de varios autores de ese país del sur. Este material literario y los poemarios publicados por su editorial son dignos de un estudio posterior que ojalá llegue a hacerse. Por ahora, nos interesan las ideas plasmadas en editoriales y artículos de fondo.

\section{¿Polémicas en Paralelo?}

La polémica, ${ }^{40}$ a la que eran tan afectos los literatos mexicanos, es otro de los aspectos que exploramos en Paralelo. El debate se origina por la publicación de dos antologías de poesía: la de la revista Estaciones y la coordinada por Raúl Leyva. La inconformidad del grupo surge, como siempre, por la inclusión y exclusión de poetas y además, se hacen juicios de valor.

La Revista Estaciones, ${ }^{41}$ en su número 12, correspondiente al invierno de 1958, publicó "Último panorama de la Poesía

40 "Una polémica puede producirse porque en un mismo momento conviven dos concepciones discrepantes acerca de las funciones que debe cumplir determinada forma" escribe Alberto Vital en La cama de Procusto, México, UNAM, 1996, p. 12. La antología es "significante de un significado que (...) se relaciona íntimamente con el efecto que la antología provoca entre el público (id., p.13).

${ }^{41}$ Estaciones fue una revista literaria que editaban Elías Nandino y Andrés Henestrosa, en la dirección estaban ellos mismos más Alí Chumacero, José Luis Martínez, Enrique Moreno de Tagle, Carlos Pellicer, Salvador Reyes Nevárez y Fernando Sánchez Mayans. Como redactores figuraban Carlos Monsiváis, Lazlo Javier Moussong, José Emilio Pacheco y Sergio Pitol y el jefe de redacción era José de la Colina. Se publicaba en cada una de las cuatro estaciones del año, de ahí su nombre. 
Mexicana", cuya presentación, sin firma, dice que es una "una apresurada selección a ojo de pájaro de la poesía que actualmente se elabora en México". Esta selección se inicia con Alfonso Reyes y concluye con José Emilio Pacheco. Están los Contemporáneos, los poetas de Taller y los de Tierra Nueva. Estaciones afirma: “Todas las presencias están justificadas por la calidad o por lo representativo; ninguna ausencia fue voluntaria". La reacción de Paralelo es de indignación: "los redactores de dicha publicación se autonombran representativos de la poesía mexicana, agrupándose en una mínima antología", destacan que el mayor error de Estaciones fue escribir en la presentación de su antología que: "Durante la Colonia y después de la Independencia el trabajo en verso no fue desdeñado, pero sólo hasta fines del siglo XIX aparecen poetas dignos de tal nombre". ${ }^{42}$ Los de Paralelo, exaltados, aseguran que "estos señores se pasaron a Sor Juana Inés de la Cruz por salva sea la parte". Aceptan que aparecen auténticos representativos de la poesía en el "Último panorama...", pero "ni están todos los que son ni son todos los que están". Se preguntan el porqué no se consideran manifestaciones poéticas del interior del territorio nacional en donde saben perfectamente, los editores, que hay "excelentes poetas que pueden incluirse entre los representativos del movimiento mexicano moderno" y que aunque estén los provincianos Jaime Sabines y Rosario Castellanos, ellos pertenecen más a la capital por haberse formado allá. Concluyen recomendándoles a los de Estaciones : "Antes de hacer temerarias y audaces selecciones tengan en cuenta que la poesía no se hace a base de sabadazos (sic)." "43 Y era muy compren-

${ }^{42}$ Estaciones, número 12, 1958, p. 369.

${ }^{43}$ Paralelo, núm. 11, p. 2.

180 \begin{tabular}{llllllllllllll}
\hline & $C$ & $A$ & L & E & I & D & $O$ & S & C & O & P & I & $O$
\end{tabular} 
sible su indignación, ya que como se aprecia en la selección de Estaciones, de los veintisiete poetas antologados, ninguno residía fuera de la Ciudad de México y aunque son nacidos entre 1899 y 1939 no aparecen ningún estridentista, ninguno de los poetas de Metáfora y por supuesto, ninguno de los de Paralelo, y sí todos los redactores y directores de Estaciones que escribían poesía, y otros poetas que quizá eran desconocidos entonces y siguen siéndolo ahora.

Otra selección cuestionada fue Imagen de la poesía mexicana contemporánea del guatemalteco Raúl Leyva. Esta antología fue publicada por el Centro de Estudios Literarios de la UNAM en 1959; en ella, dice el Diccionario mexicano de escritores, "se incluye una serie de ensayos sobre poetas mexicanos desde el posmodernismo, hasta la generación nacida entre 1922 y 1925". ${ }^{44}$ Gallardo Dávalos es quien reacciona violentamente, llama al libro de Leyva "Imagen tergiversada de la poesía mexicana". Nunca menciona al autor por su nombre, le llama "el imaginero imaginario", y le reprocha que se ocupe de hablar de poesía mexicana, siendo extranjero. Le indigna que Leyva tache a los estridentistas de falsos revolucionarios y de europeizantes, afirmando que fueron los del grupo Contemporáneos los que tuvieron esa tendencia. ${ }^{45}$ Esta airada reacción es sobre todo contra el ensayo de Leyva acerca del Estridentismo. Gallardo Dávalos, en su artículo, aprovecha para hacer una apología del movimiento al que perteneció en su juventud, intenta renovar la famosa polémica

${ }^{44}$ Diccionario de escritores mexicanos, 1967, p. 190.

${ }^{45}$ Como se ve claramente este es un rescoldo de aquella lucha individual o de grupos de los años treinta en la que "los jóvenes atacan y defienden concepciones éticas, estéticas, políticas ; llegan al extremo de impugnar rasgos de la personalidad, como la supuesta 'virilidad' o el 'afeminamiento". Víctor Díaz Arciniega, Querella por la cultura "revolucionaria", México, FCE, 1989, p. 55. 
acerca de la literatura "viril" y de paso justifica la desaparición del Estridentismo del campo literario mexicano. ${ }^{46}$

\section{CRÍTICA LITERARIA}

El grupo Paralelo hace también crítica literaria, una crítica que no es ecuánime ya que está marcada por el extremismo estridentista y por la fogosidad juvenil de los integrantes del grupo que, en ese momento, no aceptaban el valor de otros literatos que surgían con fuerza arrolladora, y a los que el tiempo ha confirmado como figuras muy importantes en la literatura nacional.

La región más transparente, de Carlos Fuentes, aparecida en 1958, no fue muy bien recibida por ellos. En un breve "Paralelograma" se la califica de "caótica" y de ser "un caso palpable del filibusterismo literario que padecemos". Luego, en un artículo firmado por Arturo Martínez Cáceres reconocen que es difícil "pretender juzgar con ecuanimidad [e] imparcialidad una obra cuya cauda de desmesurados panegíricos como de furibundos ataques ha tenido la virtud de sumir en una oportunísima confusión a sus eventuales lectores". La opinión del crítico es que la novela de Fuentes es de una "morosa y siempre innecesaria complejidad". Con "la influencia de Faulkner aún no digerida" y "recursos pseudomodernistas [...] cuya procedencia el lector menos avisado identifica [...] como proustianos, woolfianos, joyceanos, huxelyanos", y escrita en más de quinientas páginas. Considera "talentoso" a Fuentes, pero cree que debiera haber sido más "autocrítico" y quizá algún día "será un autor serio y reposado, consciente del valor de su idioma" y no alguien que calque "groseramente el tema parcial de una re-

\footnotetext{
${ }^{46}$ Paralelo, núm. 16-17, p. 3.
} 
pugnante sociedad" y que al parecer gusta de "escandalizar a los buenos burgueses". ${ }^{47}$

Octavio Paz no escapa a la crítica mordaz de Paralelo. En un editorial firmado por Miguel Ángel Ocampo titulado "El arco y la lira y el subjetivismo intransferible" $" 48$ se dice que Paz ha demostrado "dominio de la prosa y de la imagen" pero que "sus conceptos pecan de subjetivismo" porque después de muchas palabras el concepto de poesía "queda sin definir" y "son tan grandes las contradicciones del texto que sentimos que las palabras se nos caen por entre los dedos" e irrespetuosamente califica a Paz como "simpático titiritero de la palabra". $\mathrm{Al}$ parecer, nuestros entonces jóvenes poetas, se sintieron anonadados por el novedoso manejo del lenguaje del que hacían gala estos gigantes de la literatura mexicana. ${ }^{49}$

La obra de Los Contemporáneos en esta época, según dice Monsiváis, se "reexamina elogiosamente". ${ }^{50}$ Alguno de los poetas de este grupo detentan altos puestos en la política o la diplomacia, pero Paralelo los trata sin demasiado respeto. Salvador Novo no se salva de un "paralelogramazo": "Dice Salvador Novo, con una sinceridad que mucho le honra, que la prosperidad lo ha engordado y lo ha embrutecido. De acuerdo, de acuerdo." ${ }^{51}$

Torres Bodet sale peor librado. Afirman los del grupo $P a$ ralelo: "produce montones y montones de libros, de ensayos

${ }^{47}$ Paralelo, núm. 7, p. 3.

${ }^{48}$ Paralelo, núm. 5, p. 1.

${ }^{49}$ Jorge Aguilar Mora, según escribe Patricia Cabrera, Op. cit., p. 246, en otro contexto y a propósito de otros conceptos, "debatió con Paz y con Fuentes a propósito de la forma ambigua y metafórica en que usaban expresiones como 'pluralidad de sentidos', 'crítica del lenguaje' 'lenguaje crítico', 'lenguaje renovador", 'lenguaje oficial"'. Aguilar Mora los acusa de imprecisión, lo que nos demuestra que no sólo los de Paralelo se sintieron anonadados por el uso del lenguaje de los dos famosos escritores mexicanos.

${ }^{50}$ Monsiváis, Op. cit.

${ }^{51}$ Paralelo, núm. 7, p. 2. 
y poemas" pero "sus poesías siguen siendo iguales: poseen un medio tono, un sello de pequeña burguesía que las emparenta (sic) con la mediocridad". En su puesto de embajador ha hecho buena propaganda para lo nuestro entre los parisienses, "aunque sistemáticamente discrimine a los compatrietas". 52

La persona y la obra de José Vasconcelos son tildados insistentemente como reaccionarios, se dice que está en "mística decadencia" y que, "lo que deja en el tintero don Ulises Criollo es justificar porqué huyó al extranjero dejando encampanados a toda una brillante cohorte (sic) de intelectuales. Su "malinchismo se ha recrudecido y ha dado un viraje hacia el norte". En 1958 se habló de Vasconcelos como un probable candidato al premio Nobel de Literatura y Paralelo opinó : "no podemos encontrar tal clase de obras literarias ... su única obra literaria es la que se ha calificado falsamente como novelística, siendo francamente autobiográfica". Se le acusa de hispanismo y de antiindigenismo, de fanático [por su catolicismo] y de panegirista de los Estados Unidos y de Francisco Franco. Irónicamente se añade "A don Ulises José Vasconcelos le será otorgado el premio de los Juegos Florales Nobel por sus artículos periodísticos en cierta cadena de diarios". 53

En 1959 mueren Vasconcelos y Alfonso Reyes. Para el primero no hay ni siquiera una mención, al segundo, aunque a veces atacado, se le recuerda con respeto : "México y la cultura universal perdieron a uno de sus más grandes exponentes" ${ }^{54}$ Los ataques a Reyes fueron causados por haber aceptado la presidencia de la Academia y por haber dicho en una

\footnotetext{
${ }^{52}$ Paralelo, núm. 8, p. 3.

${ }^{53}$ Paralelo, núm. 4, p. 2, núm. 5, p. 2 y núm. 7, p. 1.

${ }^{54}$ Paralelo, núm. 15, p. 2.
} 
conferencia que la radio y la televisión ayudaban a fomentar la cultura.

Acerca de la crítica de sus opositores locales, Paralelo también tiene algo que decir. En Aguascalientes "tenemos una plaga (...) que ayuda grandemente a la desorientación y al cultivo del mal gusto. Nos referimos a los críticos de café, reformadores del mundo, super-sabios, aprendices de todo y maestros de nada (...) estos pobres intelectuales se sienten felices insultando impunemente y lo único que buscan es la notoriedad." $" 55$

Arremeten también contra los críticos literarios cuando escriben que en la Ciudad de México, "hay una mafia de críticos y editores. Cuando les dices la verdad (...) señalando 'errores' de sus consagrados, la gritería de cien ocas, que decía Darío, opaca la protesta." ${ }^{956}$

Cuando apareció Veredictos de polvo, de Desiderio Macías Silva, Antonio Silva Villalobos lo calificó como un libro que "no tiene frases inútiles y es de una belleza propia." embargo, el libro no fue bien recibido por otros críticos capitalinos, quizá porque desde entonces, como no hace mucho escribió Jorge Aguilar Mora, "sólo en muy raras ocasiones el ejercicio de la crítica en México se ha podido desligar de una rivalidad personal o de una complicidad de intereses (que tarde o temprano se revelan)" 58 .

Macías Silva, dieciséis años antes que Aguilar Mora, escribe el editorial del número 13-14 de Paralelo, "Los Críticos como problema", cuyas ideas parecen por momentos las del

\footnotetext{
${ }_{55}$ Paralelo, núm. 2, p. 2.

56 Paralelo, núm. 8, p. 3.

${ }^{57}$ Paralelo, núm. 12, p. 3.

58 Jorge Aguilar Mora. "Mitificación del lenguaje y mistificación del poder" en La cultura en México", suplemento de Siempre, núm. 714, 15 de octubre de 1995, p. IX.
} 
escritor de nuestros días. Como poeta confiesa la angustia por tener que estar en

...espectación (sic) permanente por los movimientos más mínimos de la acicalada metrópoli, sus dictámenes, sus descubrimientos, en pocas palabras todo lo que puede significar algo en relación con el término cultura. Se saben capaces de hacer a quien tiene la suerte de caerles bien un genio de la hora sin más méritos por parte del protegido que ese, el de haberles caído bien. Creemos sinceramente que hay irresponsabilidad en nuestros críticos. (...) se hace indispensable que muestren sus puntos de vista que han de ser seguramente muy universales cuando opinan sobre una obra.[...]Nuestra esperanza de una orientación humana, fecunda en lo que a arte se refiere, a partir de la metrópoli, no debemos cultivarla más.

Macías Silva lamenta que las obras sean simplemente desechadas sin justificación de los puntos de vista, de las orientaciones que fundamentaron la crítica adversa a las obras de escritores de provincia. ${ }^{59}$ Desiderio publicó por esos días un libro filosófico, Historicidad y destino del hombre, el cual, según Paralelo, número 15, "ha sido considerado por la crítica como uno de los mejores ensayos que sobre la materia se han hecho (...) [aunque] hubo también un comentario que no valió ni un pobre plato de Zendejas." ${ }^{" 60}$ Asientan que a este mismo crítico también "le han molestado las faltas gramaticales de Paralelo, así como la manifiesta simpatía de nues-

\footnotetext{
${ }^{59}$ Aguilar Mora hace un reproche semejante a los críticos, casi cuarenta años después que Desiderio : El lenguaje crítico de nuestro críticos culturales y políticos está plagado de lugares comunes, de frases ambiguas de contradicciones evidentes o de apologías del derecho de 'equivocarse'. (Aguilar Mora, op. cit. pp. VII y VIII)

${ }^{60}$ Se refiere con seguridad al crítico Francisco Zendejas, a quien Juan Vicente Melo consideraba junto con Jesús Arellano "los dos críticos más subdesarrollados", escribe Huberto Batis en Op. cit., p. 91.
} 
tra publicación por la Revolución Cubana. Mientras hable esa clase de críticos nos sentiremos felices."

En efecto, desde el ascenso de Castro Ruz al poder, el grupo Paralelo se percibe como abierto simpatizante de su Revolución. Hacen suyas las palabras de Pablo Neruda en su saludo al pueblo cubano, que publican en el número dieciocho: "Cuba es asunto de vida o muerte para todos nosotros". Tienen contacto con escritores cubanos y estos colaboran en la revista. En el último número publican una carta de la poeta Dulce Cañizares en la cual se queja de que "la propaganda imperialista es cobarde y mentirosa". En lugar de editorial, en ese número, aparece un fragmento de "Farsa trágica del presidente que quería una isla" poema de Efraín Huerta acerca de la invasión norteamericana a Cuba.

\section{EPÍLOGo}

Paralelo termina sin previo aviso con un número doble (19-20) fechado en junio y julio de 1962, y con la revista termina una etapa que quiso ser innovadora en Aguascalientes y que ciertamente inició un cambio de horizonte literario y en el ejercicio de la crítica. Algunos de los miembros del grupo se dedican, ahora, a actividades ajenas a la literatura, pero hasta el día de hoy conservan su amor a las bellas letras, algunos siguen escribiendo y publicando. Otros han seguido colaborando en la promoción de la cultura.

En 1991, la Universidad de Guadalajara, Xalli y el Patronato del Teatro Isauro Martínez publicaron una edición de bolsillo de poemas de Salvador Gallardo, el Hijo. Víctor M.

${ }^{61}$ ¿Alusión a la frase del Quijote?. En realidad se encuentran en Paralelo no sólo errores gramaticales sino de ortografía tan graves como espectación, egemonta, recide, exclavisante, asecho y otras muchas. 
Sandoval dejó la provincia y reside en la ciudad de México; destaca en el ambiente literario nacional por la publicación de varios poemarios, el más conocido de los cuales es Fraguas, en el que evoca la vida de provincia. Actualmente, Sandoval es presidente del Seminario de Cultura Mexicana. Desiderio Macías Silva permaneció en Aguascalientes hasta su muerte, en 1994; fue catedrático universitario y se hizo merecedor al Premio Nacional de Poesía por su libro Ascuario. Macías Silva vio publicadas local y nacionalmente varias de sus obras. En 1990 se publicó una selección de poemas titulada Postales del camino de Guillermo García Varela, aunque ahora prácticamente está alejado del ambiente literario.

La vida de Paralelo, el grupo, la editorial y la revista, fue breve pero fructífera por la trascendencia que tuvo en Aguascalientes. Sus propuestas, favorecidas por los avances en la comunicación, lograron su objetivo de iniciar el cambio del ambiente cultural, la ruptura con la vieja tradición poética, la evolución de la crítica y el reconocimiento a los artistas locales, de cualquier rama del arte.

Es a partir de la actividad de este grupo de poetas que la vida cultural y literaria del estado se transformó, pues su preocupación por la cultura rebasó las fronteras del grupo.

A instancias de Víctor Sandoval, quien fue su primer director, surgió la Casa de la Cultura, convertida ahora en el Instituto Cultural de Aguascalientes (ICA), en donde, además de fomentar todas las ramas del arte, se promueve y apoya, en los talleres literarios, la formación de nuevos escritores. El ICA rescata obras producidas por aguascalentenses en el pasado y publica la obra de nuevos escritores. La cultura se difunde hacia todos los estratos sociales por medio de las Casas de Cultura municipales.

El Premio Nacional de Poesía se ha institucionalizado y, tal como propuso Paralelo, se premia un libro, no un único 
poema. Al fallecimiento de Salvador Gallardo Dávalos se instituyó un certamen literario con su nombre, dirigido a jóvenes escritores, locales y de otros estados, en el que se premiaba un libro de poesía y otro de narrativa y se publicaban los trabajos ganadores. Desafortunadamente, no se ha convocado a este premio en los últimos años.

Sin embargo, muchos de los problemas que combatió el grupo no se han solucionado del todo. Muchos artistas siguen emigrando en busca de mejores horizontes, como lo hizo Víctor Sandoval en su momento. El reconocimiento a nuestros escritores, de ayer y de hoy, se sigue escatimando local y nacionalmente. La crítica continúa practicándose con parcialidad y, sobre todo, el centralismo no ha sido erradicado totalmente. Ojalá que la llegada del tercer milenio deje en el pasado esos problemas. 
